\title{
Investigating the Impact of Carbon Subsidy Policy on the Decision-Making of Remanufacturing Supply Chain
}

\author{
Yu ZHANG ${ }^{\mathrm{a}, 1}$, Tianshan $\mathrm{MA}^{\mathrm{a}}$ and Syed Abdul Rehman KHAN ${ }^{\mathrm{b}}$ \\ a School of Economics and Management, Chang'an University, Xi'an, China \\ ${ }^{b}$ School of Management, Xuzhou University of Technology, Xuzhou, China
}

\begin{abstract}
This research is to investigate the decision making of the members of remanufacturing supply chain under the government involvement. Different scenarios are analyzed in this research, and it is found that the subsidy for carbon emission reduction can increase the WPs (waste products) reusing. When the recycler participates in remanufacturing supply chain, the cost of remanufacturer will be shared and through centralizing the decision making, the carbon emission reduction will be enhanced and the whole supply chain's profit will decrease. So it is suggested that the government need to adjust the subsidy for carbon emission reduction in terms of the quality level of WPs and the cooperation between recycler and remanufacturer is suggested, especially in the high-value waste remanufacturing supply chain .
\end{abstract}

Keywords. Remanufacturing, carbon emission reduction, supply chain, subsidy

\section{Introduction}

The recovery processes of WPs (waste products) are mainly remanufacturing of the remanufacturable elements and crushing and reusing the left elements. Remanufacturing is to recover the remanufacturable elements' quality and performance through repair processes and technologies. While crushing and reusing the left elements is to improve material purity through material separation technology and use in industrial raw materials manufacturing. Both methods of processing the WPs are friendly to the sustainability of environment and economy [1]. Though the WPs reusing are significant for the environmental and economic situation, the cost in WPs processing is an influential factor for the implementation of WPs reusing industry [2]. The processes of WPs reusing as raw materials includes WPs acquisition, classification, crushing, and material separation, which is a long procedure and costly [3]. The WPs reusing industry needs enough investment and more entities to share the cost and risk of WPs reusing industry. With environmental problems constantly emerging, the government starts to play an indispensable role in the development of WPs reusing industry. More and more governments start to provide subsidy for the carbon emission reduction in industrial production process, including WPs reusing processes [4-5]. They encourage the WPs to be reused through the instrument of policy. For instance, the original equipment manufacturer have to acquire and reuse their wasted products.

${ }^{1}$ Corresponding Author, Yu Zhang, School of Economics and Management, Chang'an University, China; Email: 984730042@qq.com 
In fact, Zhou et al [6] concluded that the market competitiveness of the independent remanufacturer when the OEM (original equipment manufacturer) transfers the authority of remanufacturing to independent remanufacturer for a fee. This research focuses on the decision making of WPs RMSC (remanufacturing supply chain) considering the government involvement. Through analyzing the different practical scenarios of RMSC operation modes, this intend to find out the way to improve the efficiency and effectiveness of WPs reusing in terms of value creation and carbon emission reduction. This research takes an insight into the remanufacturing industry and provides an practical perspective to understand the different participants' decision making in RMSC. This paper is organized as below. In the second section, the methodology and the analysis for the decision making in RMSC is given. In the third section, the discussion and conclusion are provided.

\section{Methodology}

In WPs reusing industry, the quality level of WP is uniformly distributed in $(0,1)$, which is based on the researchers' data from several recycling companies. The recovered waste commodities are disassembled and classified into remanufacturable parts and the rest. The quality level of remanufactured elements is consistent with that of the recycled WPs. Remanufactured elements will eventually become marketable remanufactured products through the remanufacturing processes, and the left elements will be purchased by industrial raw material manufacturers. As production raw materials, both channels will produce carbon emissions, but the production process of producing new products with the materials from WPs will be less compared with that with developed primary materials. Moreover, the carbon emission reduction capacity of higher-quality remanufacturable element remanufacturing is better than the left element reusing in manufacturing industry. Further in remanufacturing, it is positively correlated with the quality level of remanufacturable elements. The government will give financial subsidies according to the carbon emission reduction in the production process. Here, the RMSC with different participants involvement is shown in figure 1.

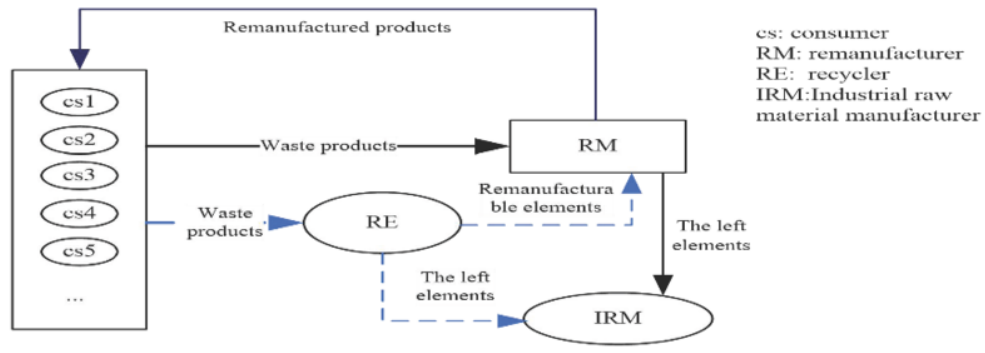

Figure 1. The RMSC with different participants involvement.

Compared with new products produced from primary materials, carbon emissions from remanufacturing and crushing and reuse will be less. For remanufacturing, with the decrease of quality level, the time of remanufacturing will be longer and the process will be more complex, which causes more energy consumption. 


\subsection{Parameters setting}

Q, the volume of WPs in the market.

$\mathrm{P}$, the price of remanufactured product

$\delta$, the quality level of a waste product, which is uniformly distributed in $(0,1)$.

$q_{r m}$, the number of WPs acquired by remanufacturer.

$q_{r c}$, the number of WPs acquired by recycler.

$q_{m}$, the number of remanufacturable elements that are selected by remanufacturer.

$q_{r}$, the number of remanufacturable elements that remanufacturer purchases for remanufacturing.

$p_{w}$, the constant parameter of acquisition price of WPs from consumers.

$p_{r}$, constant parameter of purchasing price for remanufacturable element when the remanufacturer buys remanufacturable elements from recycler.

$p_{o}$, the purchasing price of the left elements for industrial raw material manufacturer buying the left elements of WPs.

e, the carbon emission reduction for each participants in RMSC. In figure 2, the relationship between quality level $\delta$ with the carbon emission reduction in remanufacturing is given. The processing of each left element' carbon emission reduction from the WP will be the same.

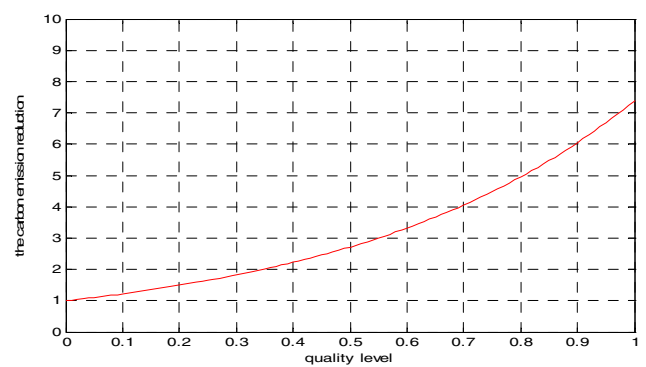

Figure 2. the relationship between quality level $\delta$ with the carbon emission reduction in remanufacturing.

$\mathrm{c}_{\mathrm{rm}}$, constant parameter for remanufacturing cost when after testing, a remanufacturable element has no need to repair. And the remanufacturing cost of a remanufacturable element is $\frac{1}{\delta^{4}} c_{\mathrm{rm}} \quad c_{p}^{m}$, the processing cost for recycled WPs when the remanufacturer does the WPs acquisition.

$c_{p}^{r}$, the processing cost for recycled WPs when the recycler does the WPs acquisition. $s_{0}$, the constant parameter of the subsidy for carbon emission reduction in one remanufacturable element remanufacturing. The subsidy for WP processing is $s_{0}$, and he subsidy for one remanufacturable element remanufacturing is $\mathrm{s}_{\mathrm{o}} \mathrm{e}^{2 \delta}$.

\subsubsection{Scenario 1}

When the remanufacturer operates the RMSC. As shown in figure 1, the WPs will be acquired and processed by the remanufacturer. Then the remanufacturable elements will be remanufactured and the left elements will be sold to the IRM (industrial raw material manufacturer). so, the profit function for the remanufaturer is, 
$\pi_{\mathrm{rm}}^{1}=q_{m}\left(\mathrm{P}+\mathrm{s}_{\mathrm{o}} \int_{\delta_{\mathrm{o}}}^{1} \mathrm{e}^{2 \delta} \mathrm{d} \delta-\mathrm{c}_{\mathrm{rm}} \int_{\delta_{\mathrm{o}}}^{1} \frac{1}{\delta^{4}} \mathrm{~d} \delta\right)+\left(\mathrm{p}_{\mathrm{o}}+\mathrm{s}_{\mathrm{o}}\right)\left(2 q_{r m}-q_{m}\right)$

$-q_{r m}\left(\mathrm{c}_{\mathrm{p}}^{\mathrm{m}}+\int_{\delta_{\mathrm{rm}}}^{1} \mathrm{p}_{\mathrm{w}} \mathrm{d} \delta\right)$

Because the quality level $\delta$ is uniformly distributed in $(0,1), \mathrm{q}_{\mathrm{rm}}=\left(1-\delta_{\mathrm{rm}}\right) \mathrm{Q}$, $\mathrm{q}_{\mathrm{m}}=\left(1-\delta_{\mathrm{o}}\right) \mathrm{q}_{\mathrm{rm}}, 1>\delta_{\mathrm{rm}}, \delta_{\mathrm{o}}>0$. To find the optimal decision making on WP acquisitions and remanufacturing quantity, the partial derivatives are calculated.

$\frac{\partial \pi_{\mathrm{rm}}^{1}}{\partial \delta_{\mathrm{o}}}=\left(1-\delta_{r m}\right) \mathrm{Q}\left[\left(\mathrm{p}_{\mathrm{o}}+\mathrm{s}_{\mathrm{o}}\right)-\left(\mathrm{P}+\mathrm{s}_{\mathrm{o}} \int_{\delta_{\mathrm{o}}}^{1} \mathrm{e}^{2 \delta} \mathrm{d} \delta\right)+\mathrm{c}_{\mathrm{rm}} \int_{\delta_{\mathrm{o}}}^{1} \frac{1}{\delta^{4}} \mathrm{~d} \delta+\right.$
$\left(1-\delta_{\mathrm{o}}\right)\left(\mathrm{c}_{\mathrm{rm}} \frac{1}{\delta_{\mathrm{o}}{ }^{4}}-\mathrm{s}_{\mathrm{o}} \mathrm{e}^{2 \delta_{\mathrm{o}}}\right)$

$\frac{\partial \pi_{\mathrm{rm}}^{1}}{\partial \delta_{\mathrm{rm}}}=\left(1-\delta_{r m}\right) \mathrm{p}_{\mathrm{w}} \mathrm{Q}-Q\left[\left(1-\delta_{o}\right)\left(\mathrm{P}+\mathrm{s}_{\mathrm{o}} \int_{\delta_{\mathrm{o}}}^{1} \mathrm{e}^{2 \delta} \mathrm{d} \delta-\mathrm{c}_{\mathrm{rm}} \int_{\delta_{\mathrm{o}}}^{1} \frac{1}{\delta^{4}} \mathrm{~d} \delta\right)+\right.$

$\left(\mathrm{p}_{\mathrm{o}}+\mathrm{s}_{\mathrm{o}}\right)\left(1+\delta_{o}\right)-\left(\mathrm{c}_{\mathrm{p}}^{\mathrm{m}}+\int_{\delta_{\mathrm{rm}}}^{1} \mathrm{p}_{\mathrm{w}} \mathrm{d} \delta\right)$

When $\frac{\partial \pi_{\mathrm{rm}}^{1}}{\partial \delta_{\mathrm{o}}}=0, \frac{\partial \pi_{\mathrm{rm}}^{1}}{\partial \delta_{\mathrm{rm}}}=0$, the optimal decision on the share of remanufacturing elements $\delta_{\mathrm{o}}$ and the share of WP acquisitions $\delta_{\mathrm{re}}$ can be obtained. Then $\mathrm{q}_{\mathrm{rm}}, \mathrm{q}_{\mathrm{m}}$ and the maximized profit $\pi_{\mathrm{rm}}^{1}$ can be calculated.

\subsubsection{Scenario 2}

When the recycler participates in waste RMSC. As shown in figure 1, the recycler does the WPs acquisition and processing, and then the remanufacturer purchases the remanufacturable elements from the recycler, and the left elements are sold to IRM.

When the two cooperators choose to do decentralized decision making in RMSC, $\mathrm{q}_{\mathrm{m}}=\mathrm{q}_{\mathrm{r}}$ and the profit functions for the recycler and remanufacturer respectively are,

$\pi_{r e}^{2}=q_{r} \int_{\delta_{\mathrm{o}}}^{1} \mathrm{p}_{\mathrm{r}} \mathrm{d} \delta+\left(\mathrm{p}_{\mathrm{o}}+\mathrm{s}_{\mathrm{o}}\right)\left(2 q_{r e}-\mathrm{q}_{\mathrm{r}}\right)-q_{r e} \int_{\delta_{\mathrm{re}}}^{1} \mathrm{p}_{\mathrm{w}} \mathrm{d} \delta-q_{r e} \mathrm{c}_{\mathrm{p}}^{\mathrm{r}}$

$\pi_{\mathrm{rm}}^{2}=q_{m}\left(\mathrm{P}+\mathrm{s}_{\mathrm{o}} \int_{\delta_{\mathrm{o}}}^{1} \mathrm{e}^{2 \delta} \mathrm{d} \delta-\int_{\delta_{\mathrm{o}}}^{1} \mathrm{p}_{\mathrm{r}} \mathrm{d} \delta-\int_{\delta_{\mathrm{o}}}^{1} \mathrm{c}_{\mathrm{rm}} \frac{1}{\delta^{4}} \mathrm{~d} \delta\right)$

To find the optimal decision making on their decision variables, the derivatives for the two profit functions (2) and (3) are used to get the Nash Equilibrium between the two parties.

$\frac{d \pi_{r e}^{2}}{d \delta_{\mathrm{re}}}=\left(1-\delta_{r e}\right) \mathrm{p}_{\mathrm{w}} \mathrm{Q}-\mathrm{Q}\left[\left(1-\delta_{o}\right) \int_{\delta_{\mathrm{o}}}^{1} \mathrm{p}_{\mathrm{r}} \mathrm{d} \delta+\left(\mathrm{p}_{\mathrm{o}}+\mathrm{s}_{\mathrm{o}}\right)\left(1+\delta_{o}\right)-\right.$

$\left.\left(c_{\mathrm{p}}^{\mathrm{m}}+\int_{\delta_{\mathrm{rm}}}^{1} \mathrm{p}_{\mathrm{w}} \mathrm{d} \delta\right)\right]$

$\frac{\mathrm{d} \pi_{\mathrm{rm}}^{2}}{\mathrm{~d} \delta_{\mathrm{o}}}=-\left(1-\delta_{r m}\right) Q\left[P+s_{o} \int_{\delta_{o}}^{1} e^{2 \delta} d \delta-\int_{\delta_{o}}^{1} p_{r} d \delta-\int_{\delta_{o}}^{1} c_{r m} \frac{1}{\delta^{4}} d \delta\right]+$

$Q\left(1-\delta_{r m}\right)\left(1-\delta_{o}\right)\left[p_{r}+c_{r m} \frac{1}{\delta_{o}{ }^{4}}-s_{o} e^{2 \delta_{o}}\right]$ 
So, when $\left.\left(1-\delta_{o}\right)\left(2 \mathrm{p}_{\mathrm{r}}+\mathrm{c}_{\mathrm{rm}} \frac{1}{\delta_{o}{ }^{4}}-\mathrm{s}_{\mathrm{o}} \mathrm{e}^{2 \delta_{o}}\right)-\mathrm{P}-\frac{1}{2} \mathrm{~s}_{\mathrm{o}}\left(\mathrm{e}^{2}-\mathrm{e}^{2 \delta_{o}}\right)+\int_{\delta_{\mathrm{o}}}^{1} \mathrm{c}_{\mathrm{rm}} \frac{1}{\delta^{4}} \mathrm{~d} \delta\right)=0$, the optimal decision on the share of remanufacturing elements $\delta_{0}$ from recycler's waste can be obtained. Then, for the recycler, the share of WP acquisitions $\delta_{\text {re }}$ from the total WPs can be obtained, when $2 \mathrm{p}_{\mathrm{w}}\left(1-\delta_{\mathrm{re}}\right)-\left(1-\delta_{\mathrm{o}}\right)^{2} p_{r}-\left(\mathrm{p}_{\mathrm{o}}+\mathrm{s}_{\mathrm{o}}\right)(1+$ $\left.\delta_{\mathrm{o}}\right)+\mathrm{c}_{\mathrm{p}}^{\mathrm{m}}=0$. Similarly, $\mathrm{q}_{\mathrm{re}}, \mathrm{q}_{\mathrm{m}}$ and the maximized profit $\pi_{\mathrm{rm}}^{2} \pi_{r e}^{2}$ in decentralized mode can be calculated.

When the two cooperators choose to do centralized decision making in RMSC, the profit functions for whole RMSC respectively are,

$\pi_{c}=q_{m}\left(P+\int_{\delta_{o}}^{1} e^{2 \delta} d \delta-\int_{\delta_{o}}^{1} c_{r m} \frac{1}{\delta^{4}} d \delta\right)+\left(p_{o}+s_{o}\right)\left(2 q_{r e}-q_{m}\right)$

$-\mathrm{q}_{\mathrm{re}}\left(\int_{\delta_{\mathrm{re}}}^{1} \mathrm{p}_{\mathrm{w}} \mathrm{d} \delta+\mathrm{c}_{\mathrm{p}}^{\mathrm{r}}\right)$

No matter in scenario 1 or 2 , for the whole RMSC, the carbon emission reduction is function (5). $e_{o}$ is the constant parameters for carbon emission reduction.

$\mathrm{e}_{\mathrm{s}}=\mathrm{q}_{\mathrm{m}} \mathrm{e}_{\mathrm{o}} \int_{\delta_{\mathrm{o}}}^{1} \mathrm{e}^{2 \delta} \mathrm{d} \delta+\mathrm{e}_{\mathrm{o}}\left(2 \mathrm{q}_{\mathrm{re}}-\mathrm{q}_{\mathrm{m}}\right)$

In centralized mode of scenario 2, it can be seen that the profit function (8) has only one difference with function (1). So the results can be obtained from the analysis result of scenario 1 . In addition, when the $\pi_{c}$ is maximized, the Pareto optimal profit for the RMSC might be achieved.

\section{Discussion and conclusion}

This research analyzed the profit creation and carbon emission reduction of RMSC in different scenarios. When the remanufacturer operates RMSC, he will decides the numbers of WPs he will acquire from consumers and the number of remanufacturable elements will be selected to be remanufactured. Compared with analysis result of the centralized decision making mode in scenario 2 , in scenario 1 , the remanufacturer can achieve the maximized profit of $\pi_{c}$ through improving the WPs processing capability to decrease the cost $c_{p}^{m}$. In fact, the participation of recycler is to share the cost burden of remanufacturer and provide his advantage of WPs processing to RMSC, especially for the relatively expensive WPs, such as waste cars.

While, for the recycler, the profit is from the remanufacturer's purchasing of remanufacturable elements and IRM's purchasing of left elements but he needs to undertake the cost of all WPs acquisition and processing of whole RMSC. When the recycler consider his own profit, the WP acquisitions will be less [7]. While for the remanufacturer, though he is no longer needs to take the WPs acquisition, but the profit is just from the remanufacturered products selling. The remanufacturing quantity is very difficult to increase when the remanufacturer just consider his own profit when making decision. Thus the carbon emission might decrease. When the taken the whole RMSC's profit into consideration, the analysis will be the same as scenario 1, and the results of remanufacturing quantity and the WP acquisitions will increase [6-7]. So when the decision making can be centralized the cost burden sharing and carbon emission reduction both can be achieved. While it is needed to consider the profit 
sharing between the two parties (remanufacturer and recycler). The subsidy from the government for the carbon emission reduction is also the profit source for the RMSC operators, which can increase the number of WPs acquisition from consumers and remanufacturing quantity. Though, constrained by the quality level of WPs, the carbon emission is mainly affected by the number of WP acquisition and remanufacturing quantity.

So, it is suggested that the remanufacturer with insufficient capital can choose to cooperate the recycler to operate the RMSC. The information sharing between remanufacturer and recycler is also advocated. When the remanufacturer has sufficient capital to operate the RMSC, the processing capability should be enhanced to decrease the cost, such as the waste transportation, dissembling and classification. The governments is suggested to adjust its subsidy for the carbon emission reduction according to the quality level of WPs of the market in order to balance the financial expenditure and environment improvement.

\section{Reference}

[1] Dou G, Cao K. A joint analysis of environmental and economic performances of closed-loop supply chains under carbon tax regulation. Comput \& Industrial Eng. 2020; 146: 1-13.

[2] Zhu M, Li X, Ma J, Xu T, Zhu L Study on complex dynamics for the waste electrical and electronic equipment recycling activities oligarchs closed-loop supply chain. Env Sci and Pollut Res. 2021; 1-21.

[3] Masanta M, Giri BC. A manufacturing-remanufacturing supply chain model with learning and forgetting in inspection under consignment stock agreement. Oper Res. 2021; 1-25.

[4] Li B, Geng Y, Xia X., Qiao D. Wang H. Comparatively Analyzing the Impact of Government Subsidy and Carbon Tax Policy on Authorized Remanufacturing. Int J Env Res and Pub Health. 2021; 18(16): $1-18$.

[5] Shekarian E., Marandi A., Majava J. Dual-channel remanufacturing closed-loop supply chains under carbon footprint and collection competition. Sus Prod and Consump. 2021; 28: 1050-1075.

[6] Zhou Q, Meng C, Yuen K F. Remanufacturing authorization strategy for competition among OEM, authorized remanufacturer, and unauthorized remanufacturer. Int J Prod Econ. 2021; 242: 1-16.

[7] Yan G, Ni Y, Yang X. Pricing and recovery in a dual-channel closed-loop supply chain under uncertain environment. Soft Comput. 2021; 25(21): 13679-13694. 